\title{
Das Categorias aos Grupos Sociais: Representações Sociais dos Grupos Urbano e Rural
}

From Categories To Social Groups: Social Representations of Urban And Rural Groups

De Las Categorías A Los Grupos Sociales: Representaciones Sociales De Los Grupos Urbano Y Rural

Mariana Bonomo, Lídio de

Souza, Maria Cristina Smith Menandro \& Zeidi Araujo Trindade

Universidade Federal do Espírito Santo
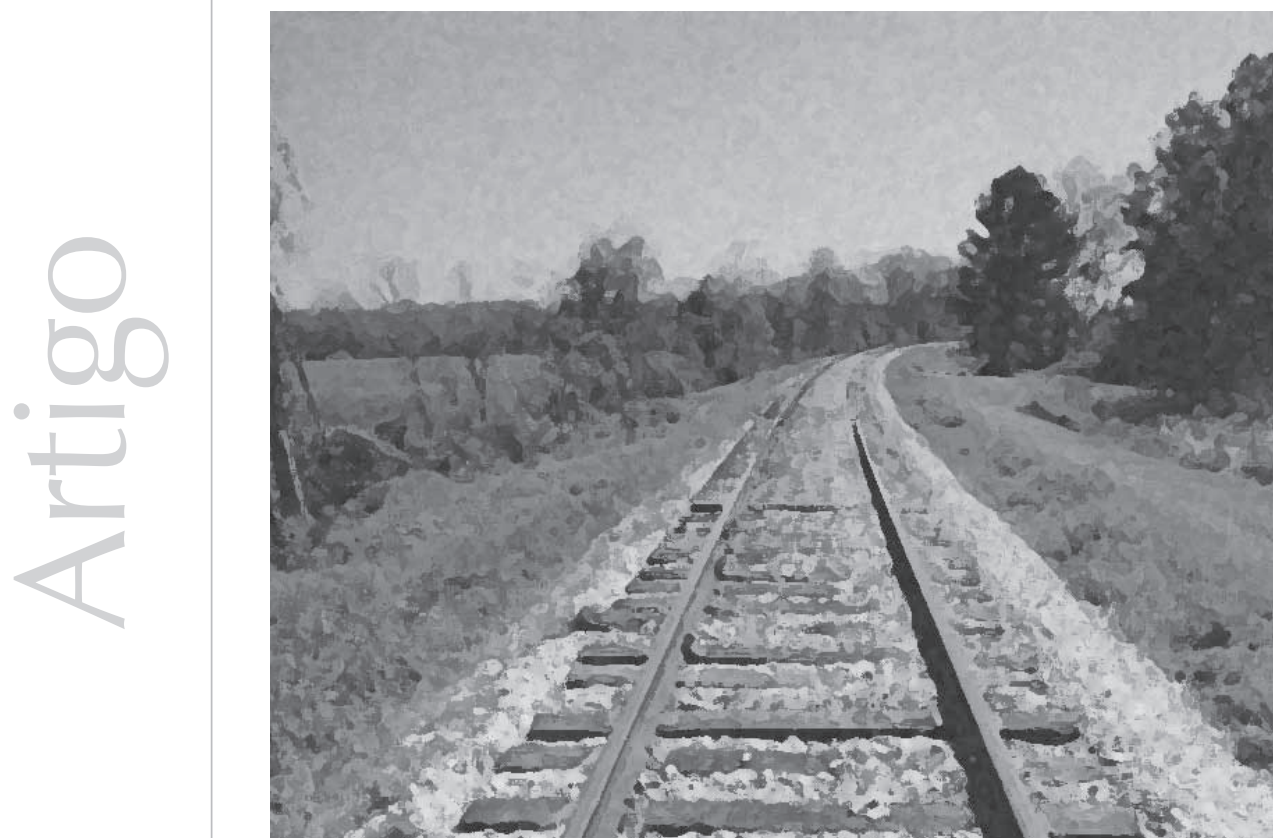
Resumo: As reflexões que conduziram o estudo focalizaram a referência entre a elaboração do campo representacional e o processo de identificação social referentes à ruralidade e à urbanidade. Esse propósito serviu-se de dois objetos que integram as categorias sociais de interesse e os grupos sociais vinculados, pessoas do meio rural e pessoas da cidade. Os corpora de dados, processados através do software EVOC2003, foram coletados por meio da técnica da associação livre a partir de entrevistas com 200 integrantes de quatro gerações de uma comunidade rural, com idades entre 07 e 81 anos. Os resultados indicaram que as representações sobre o endogrupo estão fundamentadas em estereótipos positivos, enquanto as representações sobre o exogrupo retratam a imagem dos citadinos como negativa, dinâmica que sugere um campo valorativo sustentado na ideologia, respectivamente, de um grupo com valores humanitários versus um grupo referenciado por valores capitalistas. Discute-se a função identitária do campo representacional para a manutenção da identidade social positiva do grupo rural.

Palavras-chave: Ambientes Urbanos. Grupos Sociais. Identidade. Representação social. Ruralidade

Abstract: This study was guided by reflections centred $\mathrm{n}$ the relation between the elaboration of the representational field and the process of social identification, in relation to rurality and urbanity. Two objects, which are part of the relevant social categories and their related social groups, "rural people" and "city people", were utilized for this end. The corpora of data, which was processed by using the EVOC-2003 software, was collected from interviews with 200 members, representing four generations of a rural community, and aged from 07 to 81 years old, by means of free association. The results indicated that representations of the ingroup are based on positive stereotypes while representations of the outgroup reflect a negative image of townspeople, a dynamic which suggests an evaluative field supported by the ideology of, respectively, a group with humanitarian values as opposed to a group identified with the capitalist values. The function of the representational field in maintaining the positive social identity of the rural group is discussed.

Keywords: Urban environments. Social groups. Identity. Social representation. Rurality.

Resumen: Las reflexiones que han conducido el estudio han enfocado la relación entre la elaboración del campo de representación y el proceso de identificación social, referentes a la ruralidad y a la urbanidad. Este propósito se ha servido de dos objetos que integran las categorías sociales de interés y los grupos sociales vinculados, "personas del área rural" y "personas de la ciudad". Los cuerpos de datos, procesados a través del software EVOC - 2003, han sido recolectados por medio de la técnica de la asociación libre a partir de entrevistas con 200 integrantes de cuatro generaciones de una comunidad rural, con edades entre 07 y 81 años. Los resultados han señalado que las representaciones sobre el endogrupo están fundamentadas en estereotipos positivos, mientras que las representaciones sobre el exogrupo reflejan la imagen de los citadinos como negativa, dinámica, que sugiere un campo valorativo sustentado en la ideología, de un grupo con valores humanitarios versus un grupo referenciado por valores capitalistas. Se discute la función identitaria del campo representacional para el mantenimiento de la identidad social positiva del grupo rural.

Este artigo é parte da Tese de

Doutoramento da autora principal, trabalho intitulado

"Identidade social

e representações sociais de rural

e cidade em um contexto rural comunitário: campo de antinomias", projeto de pesquisa vinculado à

Rede de Estudos e Pesquisas em

Psicologia Social (RedePso) da Universidade Federal do Espírito Santo.

Apoio: $\mathrm{CNPq}$ e CAPES/PDEE

Palabras clave: Ambientes urbanos. Grupos sociais. Identidad. Representación social. Ruralidad.

No contexto social contemporâneo, a ruralidade como expressão identitária tem provocado um forte debate sobre o destino das comunidades camponesas e dos indivíduos que se identificam com o modo de vida rural (Albuquerque, 2002; Stropasolas, 2006), visto que os "modos de vida urbanos tornaram-se padrões de existência social largamente partilhados" (Costa, 2002, p. 18), influenciando a forma como as pessoas conduzem suas vidas e favorecendo o surgimento de novas sociabilidades.

Naiff, Monteiro e Naiff, em investigação sobre as representações sociais de camponês e de agricultor para estudantes no contexto universitário, constataram a associação do primeiro à ideia de atraso e de pobreza, e a do segundo, à modernidade e à integração aos novos recursos produtivos. Os autores concluem o estudo indagando sobre "como os que ainda se identificam como camponeses estão vivenciando este momento histórico, principalmente pelas estratégias de influências minoritárias... utilizadas como resistência às tentativas de aniquilamento identitário em curso" (2009, p. 226). Henri Tajfel, ainda na década de 1950, fazia uma indagação semelhante: considerando que os indivíduos buscam manter uma 
autoimagem positiva, mecanismo que se realiza no contexto grupal, como os grupos minoritários mantêm sua identidade social positiva? Esse questionamento tem profunda relevância para a análise das relações sociais na atualidade, pois, como discute Costa, argumento também compartilhado por Burity (2001) e Souza (2008), nós nos deparamos com um paradoxo identitário:

à medida que os processos contemporâneos de globalização se intensificam e se alargam, envolvendo poderosíssimas dinâmicas de interligação e intercâmbio, de comunicação e difusão em termos mundiais, as identidades culturais diferenciadas, específicas, fragmentadas, ou mesmo marcadamente particularistas, em vez de se esbaterem ou desintegrarem, parecem tender a proliferar, a multiplicar-se e a acentuar-se (Costa, 2002, p. 15)

É o que constatam Cerqueira (2000), em uma comunidade rural portuguesa, Silva (2004), em comunidades de assentamentos rurais no Brasil, Almeida (2006), no campesinato do Mato Grosso do Sul, e Cantarelli (2006), nas comunidades rurais tradicionais. Esses trabalhos evidenciam a participação ativa dos grupos sociais considerados de status inferior e o processo que empregam na elaboração e na preservação de sua identidade social. Como analisa Moscovici, "as minorias até então passivas reclamam sua autonomia, tornam-se minorias ativas" (2009, p. 672), constituindo esse um fenômeno que reivindica uma abordagem psicossocial. A teoria das representações sociais apresenta-se, então, como estratégia analítica e metodológica adequada para o conhecimento do objeto que nos desafia no presente estudo: o imaginário social vinculado à realidade rural no contexto da cultura comunitária.

Reconhecida como ferramenta teóricometodológica de grande relevância para o campo de produção científica acerca de diversos objetos sociais, a teoria das representações sociais (Jodelet, 2001;
Moscovici, 2003) tem contribuído largamente para a compreensão do pensamento social expresso na rede simbólica dos grupos e objetivado nas relações e práticas cotidianas. No que concerne às representações sociais como sistemas de interpretação da realidade, Vala ressalta que:

os indivíduos constroem representações sobre a própria estrutura social e as clivagens sociais, e é no quadro das categorias oferecidas por essas representações que se autoposicionam e desenvolvem redes de relações, no interior das quais se produzem e transformam as representações sociais. Quer dizer, por um lado, as representações sobre a estrutura social, enquanto variável independente suscitam sistemas de categorização ou grupos sociais; mas, por outro, as representações sociais, enquanto variável dependente, são construídas no interior dessas categorias ou grupos sociais (Vala, 1997, p. 381)

É a partir desse processo de construção, apropriação e funcionamento dos sistemas representacionais, e considerando que as representações intervêm "em processos tão variados como a difusão e a assimilação de conhecimento, a construção de identidades pessoais e sociais, o comportamento intra e intergrupal" (Cabecinhas, 2004, pp. 2-3), que devemos considerar a manifestação de identidades mobilizadas pelas categorias e grupos sociais de pertencimento. Os grupos fronteiriços ao endogrupo revelam-se como elementos de contraste fundamental nesse processo. Oposição e complementaridade são a matriz onde tomam forma a identidade e a alteridade que orientam as relações entre os grupos sociais. A análise de Jodelet esclarece:

O outro, como 'não-eu', 'não-nós', deve ser afastado ou tornar-se estranho pelas características opostas àquelas que exprimem o que é próprio da identidade. O trabalho de elaboração da diferença é orientado para o interior do grupo em termos de proteção; para o exterior, em termos de tipificação desvalorizante e estereotipada do diferente. Nessa construção se movem interesses que 
servem à comunidade, no interior da qual se define a identidade (1998, p. 51)

Vinculada à chamada grande teoria, a abordagem estrutural das representações sociais (Abric, 2001, 2003a, 2003b) tem fornecido bases conceituais apropriadas ao tratamento e à análise de dados no intuito de identificar os significados e a estrutura da representação social, possibilitando a sistematização do campo representacional e a análise comparativa entre dois objetos ou de um mesmo objeto abordado em diferentes grupos. Essa perspectiva se fundamenta na hipótese de que o campo estrutural de uma representação social se organiza a partir de um núcleo central, caracterizado pela memória coletiva, que comporta os valores dos grupos sociais e reflete a base compartilhada da significação de determinado objeto, e que tem nas condições socio-históricas sua matriz de produção (Pecora \& Sá, 2008). O núcleo central tem por função gerar ou transformar os demais significados, além da função organizadora que determina o tipo de ligação entre os elementos que compõem o campo representacional de determinado objeto (Sá, 1996). Para entender essa dinâmica, conforme explica Galli (2006), é necessário considerar o valor simbólico e o poder associativo da representação, uma vez que "evocar um objeto remete necessariamente aos elementos centrais de sua representação, da mesma forma em que a evocação desses elementos nos retorna ao objeto" (p. 45 - tradução nossa). A vinculação entre os elementos centrais e o objeto de representação é, portanto, uma ligação sempre de natureza simbólica. Enquanto o núcleo central tem como propriedade essencial a estabilidade, o sistema periférico é mais flexível, tendo as seguintes funções, de acordo com Flament (2001): (1) prescrever comportamentos e tomadas de posição por parte dos indivíduos, (2) possibilitar uma personalização das representações e dos comportamentos associados, e (3) proteger o núcleo central, contribuindo para sua estabilidade e resistência a mudanças. Todavia, ainda que as representações sociais sejam consensuais graças ao núcleo central, os elementos da periferia indicam a incorporação da variabilidade individual ao sistema, a partir da história e da experiência dos indivíduos, atualizando e dando mobilidade ao campo sem, contudo, comprometer o conteúdo e a estrutura da representação.

Essas reflexões conduziram o estudo para a investigação das possíveis relações entre o campo representacional e o processo de identificação social, tendo como referências as categorias sociais ruralidade e urbanidade, para membros de uma comunidade rural. Para tanto, procuramos identificar os elementos de representação que constituem as representações sociais de pessoas do meio rural e pessoas da cidade, cuja função é integrar os grupos sociais às categorias de pertencimento.

\section{Método}

\section{Participantes}

A amostra foi composta por 200 moradores de uma comunidade rural distribuídos entre quatro grupos geracionais com 50 participantes cada, de acordo com seguinte distribuição etária: quarta geração: idades entre 07 e 12 anos; terceira geração: idades entre 15 e 25 anos; segunda geração: idades entre 35 e 45 anos, e primeira geração: indivíduos com 60 anos ou mais, sendo que, nesse grupo, a idade máxima foi de 81 anos. A seleção dos participantes para cada grupo geracional se baseou em dados censitários da comunidade coletados durante pesquisa anterior ao presente estudo.

Em cada geração, foram entrevistadas 25 pessoas do sexo feminino e 25 do sexo masculino. Todos os integrantes da terceira e da quarta gerações eram solteiros, os da segunda geração, casados (98\%) ou 
divorciados (2\%), e os da primeira geração, casados (82\%) ou viúvos (18\%). Informamos que o sexo foi considerado apenas para equilibrar a distribuição dos participantes nos diferentes grupos geracionais, não sendo uma variável de interesse para a análise dos dados.

\section{Procedimento de coleta dos dados}

As entrevistas foram realizadas individualmente nos diferentes espaços da comunidade (escolas, botecos, igrejas, praças, associação/ cooperativa e unidade de saúde) ou nas residências dos próprios participantes, conforme previamente acordado. Apoiados na Resolução do Conselho Federal de Psicologia acerca da realização de pesquisa em Psicologia com seres humanos, avaliamos que o estudo ofereceu risco mínimo aos participantes, uma vez que os procedimentos não os sujeitaram "a riscos maiores do que os encontrados nas suas atividades cotidianas" (Conselho Federal de Psicologia, 2000, p. 4). De todo modo, após serem informados dos objetivos e dos procedimentos, todos os participantes (no caso da quarta geração, os seus responsáveis) assinaram o Termo de Consentimento Livre e Esclarecido para participação em pesquisas científicas.

\section{Instrumentos e procedimento de tratamento dos dados}

$\mathrm{O}$ instrumento de coleta dos dados consistiu em um roteiro de entrevista estruturado, conforme a técnica de associação livre (Abric, 2003b), contendo três tópicos de informação:

(1) dados sobre a identificação do participante,

(2) questões de associação livre (o que você pensa, sente ou imagina quando eu falo...) para pessoas do meio rural e pessoas da cidade, e (3) questões de contextualização das evocações (por que é assim).

O conjunto de palavras ou expressões vinculadas a cada objeto, obtido por meio da associação livre, foi processado através do software EVOC-2003 (Ensemble de Programmes_L'Analyse des Évocations) (Vergè, 2000). Esse programa fornece um quadro com quatro quadrantes nos quais é possível identificar os elementos mais significativos do campo representacional, posicionados de acordo com sua importância na estrutura do objeto representado, segundo critérios de frequência e ordem de evocação. O quadro é sistematizado da seguinte forma: a parte superior esquerda refere-se ao núcleo central (itens mais frequentes e mais prontamente evocados); a inferior esquerda (elementos com menor frequência e mais prontamente evocados, também conhecida como zona de contraste) e a superior direita (elementos com alta frequência e menos prontamente evocados) formam a primeira periferia ou a periferia próxima, e, finalmente, a inferior direita (itens menos frequentes e menos prontamente evocados) compõe a segunda periferia ou a periferia distante (Abric, 2003b; Sá, 1996). Os dados provenientes das justificativas do conteúdo evocado foram categorizados segundo as orientações da análise categorial temática, como sugerido pela análise de conteúdo (Bardin, 2002, 2003), e os dados sociodemográficos foram sistematizados por meio de procedimentos estatísticos descritivos.

\section{Resultados e discussão}

A distribuição das evocações concernentes aos objetos pessoas do meio rural e pessoas da cidade, segundo as gerações do grupo rural, encontra-se na Tabela 1. Embora ambos os objetos tenham apresentado tanto elementos valorados negativamente quando positivamente, ressaltamos que, em função da saliência dos significados vinculados a esses objetos, após o processamento do banco de dados, o software EVOC manteve nos quadrantes apenas elementos positivos para pessoas do meio rural e negativos para pessoas da cidade. No banco de dados inicial, já se podia notar, para o primeiro objeto, a predominância de elementos avaliados como positivos (primeira geração, 
94.84\%; segunda, 94.50\%; terceira, 87.64\%, e quarta, 94.02\%) e para o segundo, majoritariamente, elementos avaliados como negativos (primeira geração, $81.53 \%$; segunda, $87.40 \%$; terceira, $75.20 \%$, e quarta, $67.62 \%)$.

Tabela 1. Análise hierarquizada das associações livres para os termos indutores pessoas do meio rural e pessoas da cidade

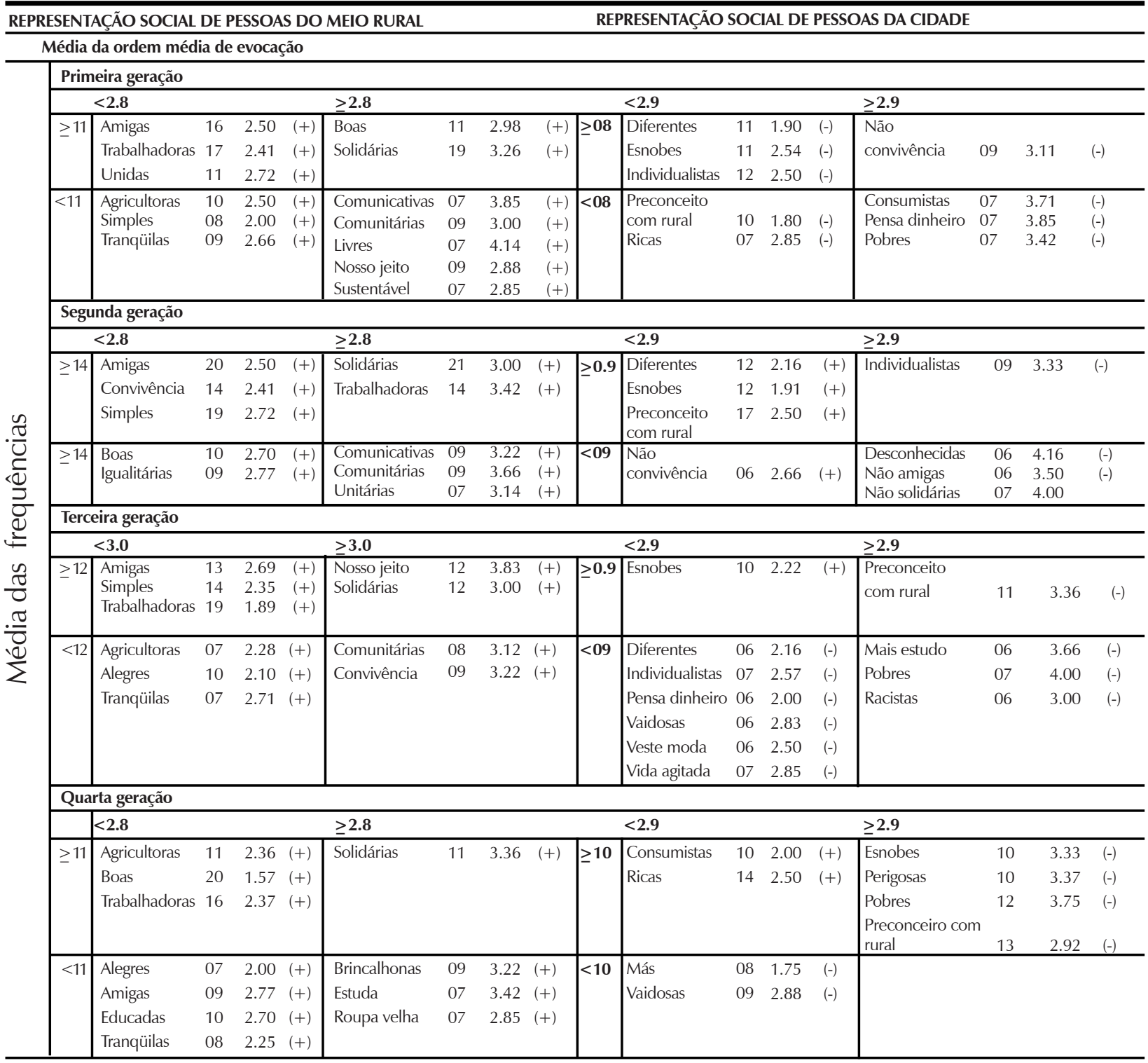

Nota: sequência de apresentação dos dados: termo evocado - frequência - média da ordem média de evocação polaridade. Foram condensados nesta tabela os quadrantes referentes às pessoas do meio rural e pessoas da cidade, especificados segundo as quatro gerações investigadas.

Os elementos provavelmente nucleares da representação social de pessoas do meio rural são agricultoras, amigas, boas, convivência, simples, trabalhadoras e unidas, sofrendo variações 


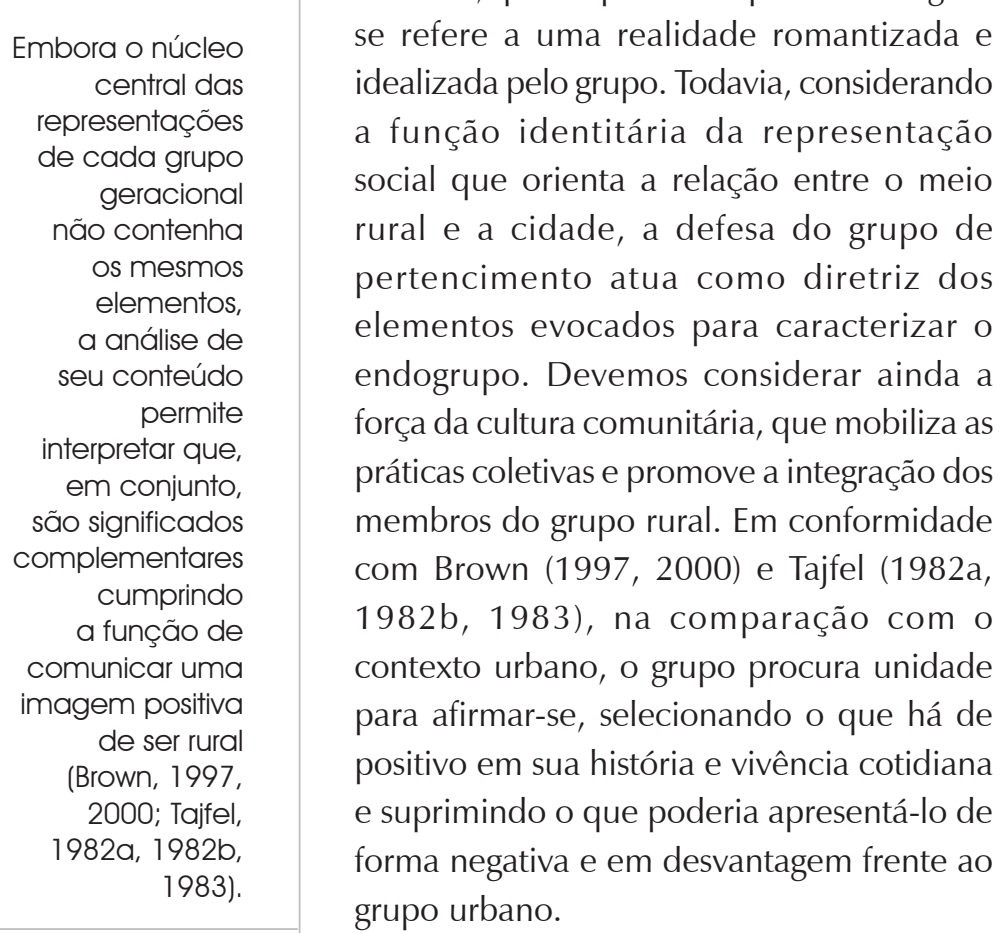

Embora o núcleo central das representações de cada grupo geracional não contenha os mesmos elementos, a análise de seu conteúdo permite interpretar que, em conjunto, são significados complementares cumprindo a função de comunicar uma imagem positiva de ser rural (Brown, 1997, 2000; Tajfel, 1982a, 1982b, 1983). O campo representacional é completado com os temas solidárias, tranquilas, igualitárias, nosso jeito, alegres e educadas, localizados na primeira periferia, e ainda comunitárias, livres, sustentáveis, comunicativas, brincalhonas, estuda e roupa velha, na segunda periferia. Chama a atenção o elemento roupa velha no quarto grupo geracional, que ilustra o tipo de vestuário mais característico da atividade agrícola, que, para essa geração, parece transmitir a ideia de informalidade entre as pessoas do território. Entre os demais elementos, não encontramos especificidades, o que evidencia uma forte coesão simbólica em relação ao significado desse objeto para o grupo rural. Assim, visualizamos esse conjunto de dados como afirmação do vínculo com o modo de vida camponês, baseado no trabalho agrícola, no sistema comunitário e na forte convivência entre os membros do grupo, que favorece a integração e o estabelecimento de práticas coletivas e facilita a transmissão intergeracional.

A interpretação dos participantes acerca do que levaria as pessoas do meio rural a serem tais como foram representadas foi fundamentada em motivos que focalizaram: (1) o nível individual retratando atributos pessoais positivos ( $f=22$ ) - "Acho que porque quem nasce aqui na roça, já nascemos com o nosso jeito de roceiro. A gente não muda o nosso jeito para ir para a cidade. Somos pessoas boas e solidárias"; (2) a família como mediadora da formação das pessoas ( $f=75)$ - "Desde que nasce, vai aprendendo de geração em geração. Você vai trabalhando e aprendendo que não pode fazer nada sozinho, tem que achar o amigo pra te ajudar... vai aprendendo o certo. É por causa da educação que tem, vem do nosso povo mesmo, desde os pais. Lá na cidade, não tem educação. Os pais da roça é que educa", e (3) o próprio contexto rural através da comunidade, do modo de produção e do compromisso solidário entre as pessoas $(f=$ 76) - "Vem do jeito do povo do lugar. Você topa um ambiente bom e agradável, você fica uma pessoa bacana, já é o jeito e o sistema do lugar. Me dei muito bem aqui, muito apoiado... só se no céu for melhor. Temos tempo, temos liberdade, somos autônomos. Isso facilita a gente a ter amigos".

O contexto das comunidades tradicionais apresenta-se como realidade favorável ao desenvolvimento de relações sociais mais próximas e à mobilização de seus integrantes para projetos cotidianos compartilhados. $\mathrm{Na}$ realidade rural, a cultura comunitária favorece a convivência entre as famílias e as pessoas do território, sociabilidade possibilitada também pela maior flexibilidade de tempo 
devido ao modo de produção baseado na agricultura familiar (Moreira, 2005), o que permite o envolvimento em práticas coletivas e nas diferentes prioridades da vida local, conforme os elementos que compõem o campo representacional das pessoas do meio rural. No contexto das práticas coletivas, as atividades de interação vão dando contorno à identidade grupal e fortalecendo a identificação social de seus membros. É o que se constata em alguns estudos que discutem a construção de identidades a partir de contextos grupais ou de arranjos sociais segundo a cultura comunitária, como no caso de grupos ciganos (Souza, Bonomo, Livramento, Brasil, \& Davel, 2009), pomeranos (Bahia, 2001), japoneses (Suda \& Souza, 2006) ou do candomblé (Rabelo, 2008).

Na esfera da unidade familiar, podemos destacar a importância de sua função socializadora para a transmissão de valores, crenças, normas e códigos afetivos como recursos simbólicos para a vida no grupo (Doise, 2002). Os mecanismos de socialização no território comunitário proveem os indivíduos de elementos para a simbolização da realidade dentro e fora do campo endogrupal, cumprindo a função de orientá-los nos diferentes contextos de interação social. As representações acerca dos objetos relevantes ao grupo (inclusive o próprio grupo como objeto representacional, como abordado neste estudo) tornam-se instrumentos-chave para a condução das relações intergrupais (imaginário refletido nos dados referentes ao objeto pessoas da cidade, como poderá ser verificado), visto que as representações são "uma forma de conhecimento, socialmente elaborada e partilhada, com um objetivo prático, e que contribui para a construção de uma realidade comum a um conjunto social" (Jodelet, 2001, p. 22).

As evocações derivadas do termo indutor pessoas da cidade revelaram conflito entre os espaços de pertencimento rural e a cidade, segundo o sistema interpretativo dos participantes. Os temas diferentes e preconceito com o rural indicam a comparação intergrupal, acompanhados dos elementos esnobes, individualistas, consumistas e ricas, que expressam crítica em relação ao modo de vida urbano, que estaria fundamentado em valores capitalistas, enquanto o grupo rural se funda em valores humanitários (como pode ser conferido no campo representacional de pessoas do meio rural). A primeira periferia desdobra o sentido expresso no núcleo central - pensa em dinheiro, vaidosas, vida agitada e veste moda - e, como consequência dos valores anunciados no sistema central, sugere o estabelecimento de vínculos sociais fracos (não convivência), desigualdade social (pobres), além de adjetivações que caracterizam as pessoas da cidade como uma ameaça (más e perigosas). A periferia distante concentra elementos que complementam a atribuição de sentido negativo ao grupo urbano (desconhecidas, não amigas, não solidárias e racistas), compondo um campo representacional que indica, claramente, a delimitação de uma fronteira simbólica entre os dois grupos.

As justificativas para as evocações provocadas pelo termo indutor pessoas da cidade também estiveram referenciadas nos níveis individual, familiar e contexto mais geral, este último nomeado sociedade ou sistema. Assim, explicam a constituição do urbano através: (1) do indivíduo cuja autoimagem estaria centrada na crença de superioridade, inerente aos citadinos ( $f=43$ ) - "Eles acham que o pessoal da roça é mais bobo, eles discrimina o pessoal da roça. Eu acho que é porque se trata mesmo da cidade e da roça, porque eles são da cidade e se acham melhor. Quando eles falam da cidade, parece que são poderosos, se acha melhor. Como se fossem superiores! Eles recebem as novidades primeiro, falam que a língua deles é culta e a nossa é jeca. É uma coisa sempre de cima para baixo... uma ideologia, sabe? Uma hierarquia que vai 
sendo passada"; (2) da família urbana como instituição que não proporciona formação adequada a seus membros $(f=11)$ - "Lá não tem orientação das famílias, é tudo largado. Não aprenderam nas famílias, o ambiente de lá é diferente", e (3) da sociedade/ sistema, que atuaria como mecanismo de produção das características associadas às pessoas da cidade $(f=96)$ - "Talvez eles têm necessidade dessa aparência lá, e já no campo se prega mais a essência da pessoa. Porque os próprios modos de vida e o jeito de viver faz ser assim. A pessoa só por ser empregado, por ter patrão, já faz a pessoa ter que ir se preparando. A questão do individualismo impossibilita a solidariedade, porque você tem que ver só o seu. O ser humano da cidade não nasce assim, mas o sistema lá não permite desenvolver outras características e modos".

Os resultados apoiados nas representações sobre o exogrupo explicitam o processo de distintividade positiva do endogrupo, contexto em que a imagem do grupo tido como opositor é elaborada a partir de atributos valorados de forma negativa (Brown, 1997, 2000). Nesse processo, verifica-se o compartilhamento de um campo representacional polarizado (endogrupo positivo versus exogrupo negativo), conteúdo que serve de substrato para a construção de tal dinâmica representacional. A tonalidade do processo de comparação vai sendo constituída gradualmente (de tranquilas a vida agitada ou de solidárias a não solidárias, por exemplo) envolvendo elementos destacados a partir do contato entre os grupos e em circulação na mídia (Tabela 1). Ainda nesse conjunto de dados, é interessante destacar que os mecanismos identificados pelos participantes como responsáveis pela profusão das características referentes aos citadinos (como inerentes aos indivíduos ou como fruto da formação familiar e societária) são interpretados como tendo sido corrompidos pela estrutura capitalista que regeria a vida nas cidades, enquanto no meio rural esses mesmos mecanismos são estrategicamente percebidos como responsáveis pelos atributos positivos de seus membros.

Como processo associativo subjacente à comparação entre rural e cidade, o contraste entre ricos e pobres imprimiu uma segunda dimensão às temáticas que compõem o campo representacional estudado. A associação de pessoa da cidade à pessoa rica versus pessoas do campo e da favela/pobres expressa a defesa pelo grupo rural da categoria pobres, interpretada como constituída por pessoas do meio rural que, por impossibilidade de permanência no campo, tiveram que migrar para zonas urbanas formando/ocupando as áreas de favelas. Cavassani (1998) verificou semelhante processo de identificação em pesquisa com policiais. Segundo a autora, na base da recusa do uso de violência contra presos por parte de alguns profissionais, encontrava-se o processo de identificação social. Embora esses policiais fossem formados em uma instituição cujo discurso dominante se fundamentava em práticas violentas, solidarizavam-se com os presos provenientes da mesma inserção social, marcadamente de camadas mais pobres, vivendo a contradição entre a identidade do profissional policial e a identidade vinculada à sua categoria social de origem, tensão que gerava adoecimento entre os integrantes desse grupo. O processo de identificação social, nesse contexto, "esconde negociações de sentido, choques de interesse, processos de diferenciação e hierarquização das diferenças, configurando-se como estratégia sutil de regulação das relações de poder, quer como resistência à dominação, quer como seu reforço" (Sawaia, 2001, p. 123).

\section{Campos representacionais em comparação}

Como representantes da realidade simbolizada (Abric, 2001, 2003a, 2003b), as 
representações sociais favorecem os estudos sobre os grupos sociais, permitindo sua abordagem a partir da dimensão psicológica de pertencimento (Brown, 1997, 2000; Tajfel, 1982a, 1982b, 1983), perspectiva que assumimos como referência-chave para a reflexão sobre os resultados. A análise semântica do campo representacional, a partir dos elementos constituintes das representações estudadas (Tabela 1), sugeriu coesão simbólica entre os dados dos grupos geracionais, fornecendo um imaginário compartilhado acerca das representações endo e exogrupais. Tajfel explica que o contexto intergrupal conduz a um sistema simbólico conjugado, pois "quanto mais perto estamos da polaridade intergrupo..., mais uniformidade haverá da parte das pessoas que pertencem a certos grupos, na sua conduta para com os membros do grupo-dos-outros" (Tajfel, 1982a, pp. 16-17), e, seguindo essa orientação, mais os indivíduos que pertencem a outros grupos serão percebidos como massa não diferenciada, processo conhecido como estereotipia. Nesse sentido, a fim de evidenciar a relação intergrupal expressa nas representações em análise, integramos os corpora de dados dos grupos geracionais compondo um único banco por objeto. A partir da análise hierarquizada das associações livres, realizada pelo software EVOC-2003, procedemos à comparação entre o sistema central e a periferia próxima dos objetos abordados, conforme a Figura 1.

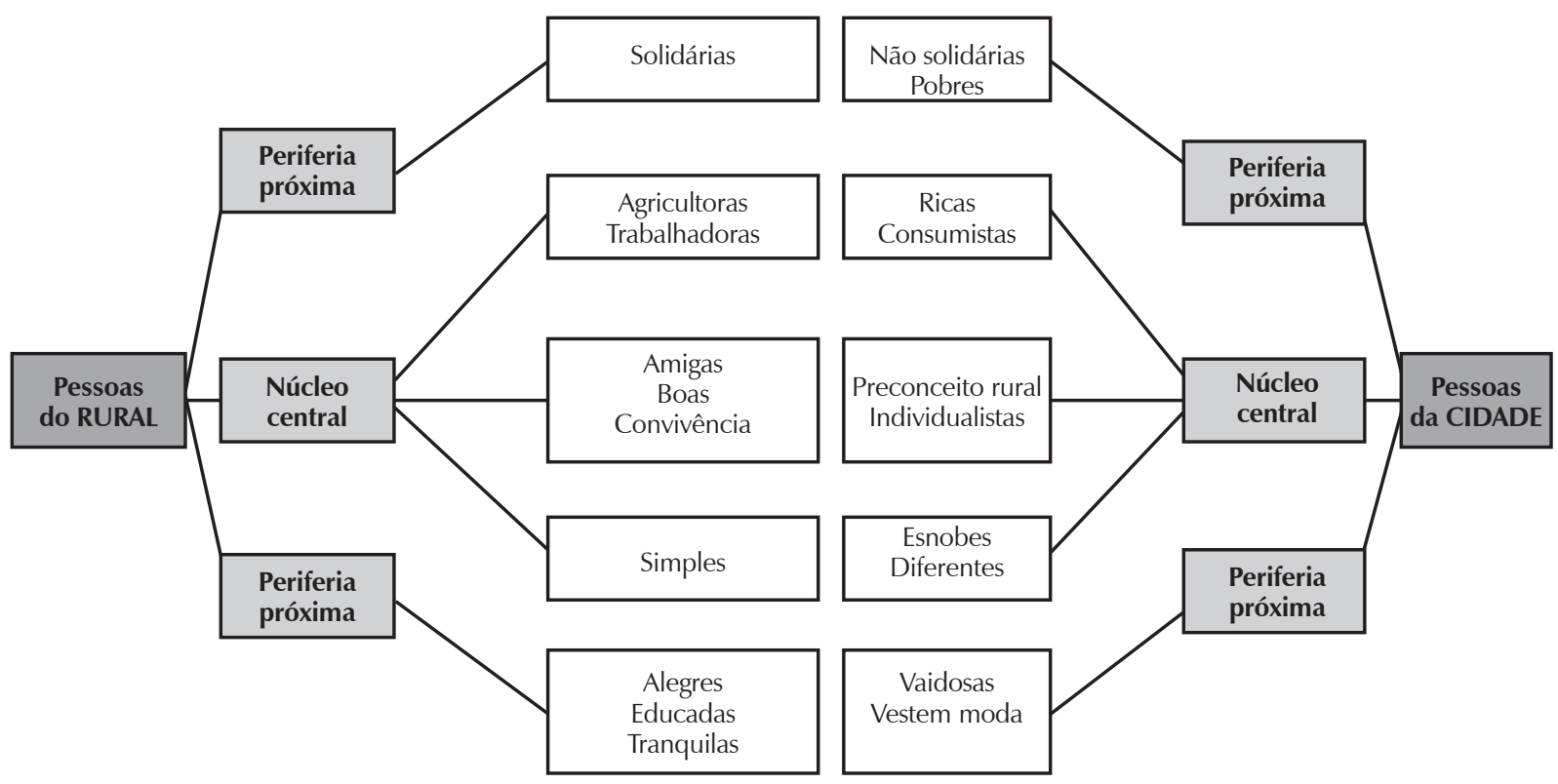

Figura 1. Esquema comparativo entre as representações sociais dos objetos pessoas do meio rural e pessoas da cidade a partir da análise hierarquizada das associações livres. Para o estabelecimento do quadrante de pessoas do meio rural: frequência limite $=36$ e média de evocação $=2.9$, e para o quadrante de pessoas da cidade: frequência limite $=20$ e média de evocação $=2.9$

No sistema central das representações endo e exogrupais, são destacados, respectivamente: o trabalho e a agricultura como práticas e valores do grupo rural, em contraste com a imagem da riqueza e do consumismo, status e valor que reforçam a associação de pessoas da cidade a pessoas ricas; as relações de proximidade entre os membros da comunidade (convivência e amizade), mediadas por práticas de solidariedade (bondade) que fortalecem a imagem do coletivo, enquanto, na cidade, prevalece o individualismo como referência de conduta, processo de distinção que se relacionaria ainda ao preconceito contra o grupo rural, e, por fim, o eixo temático da simplicidade, que retrata o povo do campo a partir da condição de igualdade (na forma de falar, 
De acordo com Mazzara (1997) e

Sadiqi (2008), o termo estereótipo surgiu no contexto da tipografia por volta do século XVIII, referindo-se à reprodução de imagens impressas através de formas fixas, e foi introduzido no campo das ciências sociais pela primeira vez em 1922, pelo jornalista Walter Lippmann, já com o significado de mecanismo de simplificação do mundo, um dos processos elementares da categorização social (Brown, 1997, 2000). de vestir e sem hierarquia socioeconômica), em comparação com a caracterização das pessoas da cidade como diferentes e esnobes. A primeira periferia, estreitamente conectada aos significados do núcleo central, apresenta em oposição os elementos solidárias para as pessoas do meio rural e não solidárias para as pessoas da cidade, o que, segundo os respondentes, provocaria/manteria a condição de pobreza em determinados segmentos das sociedades urbanas. Os elementos alegres, educadas e tranquilas marcam o estilo do grupo rural, enquanto as pessoas da cidade são representadas como vaidosas e vestem moda.

Entre as funções destacadas por Abric (2003a), a função identitária das representações sociais parece assumir a orientação central do conteúdo expresso nas representações investigadas. A Figura 1 indica o recrutamento de estereótipos para referendar a lógica de distinção grupal (Brown, 1997, 2000; Tajfel, 1982a, 1982b, 1983), sendo o endogrupo associado a estereótipos positivos e o exogrupo, a negativos. De acordo com Mazzara (1997) e Sadiqi (2008), o termo estereótipo surgiu no contexto da tipografia por volta do século XVIII, referindo-se à reprodução de imagens impressas através de formas fixas, e foi introduzido no campo das ciências sociais pela primeira vez em 1922, pelo jornalista Walter Lippmann, já com o significado de mecanismo de simplificação do mundo, um dos processos elementares da categorização social (Brown, 1997, 2000).

O conteúdo e a dinâmica do campo representacional estudado, especialmente no que se refere à representação do exogrupo, apresentam coerência com as características dos estereótipos apontadas por Mazzara (1997), compartilhamento social, generalização das características elucidadas e ainda consistência ou rigidez dos significados, posto que as representações dos grupos abordados têm, principalmente nos elementos do núcleo central, a expressão de sua saliência para o grupo respondente e guardam forte associação com as normas, as crenças e os valores que compõem o padrão sociocultural das sociedades, sendo, portanto, realmente mais estáveis ou rígidas (Abric, 2001; Sá, 1996). A análise ampliase na possibilidade de discutir as funções de tais estereótipos para o grupo rural. $\mathrm{Na}$ concepção de Tajfel (1982a), os estereótipos têm, segundo a sua dimensão social, as seguintes funções:

(1) Justificação social, que, para os chamados grupos superiores, consiste na produção de ideologias para justificar o lugar de superioridade que ocupam, e, nos grupos minoritários, como é o caso do rural, atua na ressignificação dos estereótipos negativos que Ihes são atribuídos. O trabalho de elaboração de significados que representem positivamente o rural afasta a possibilidade de identificação com os estereótipos negativos (largamente divulgados e reforçados no imaginário social, especialmente através dos meios de comunicação), evitando que os integrantes do grupo se reconheçam como jecas, bobos ou feios, entre outros (Aleixo, 2004; Fressato, 2008; Oliveira, 2003), mas, ao contrário, ressaltem os atributos positivos de seu pertencimento, conforme conteúdo intragrupal inscrito na Tabela 1 e na Figura 1;

(2) Explicação causal, cuja função é produzir explicações simples como estratégia de ordenamento da complexa dimensão social. Os resultados sugerem a atuação de dois sistemas valorativos distintos - o meio rural como humanitário e a cidade como capitalista - que se constituem na base interpretativa para a explicação e a justificativa das práticas e representações adotadas pelo grupo, conforme evidenciado no conjunto de dados referente às justificativas das evocações (dimensão individual, familiar e societária);

(3) Diferenciação positiva, função que está claramente ilustrada na polaridade do campo representacional dos grupos 
como objeto. Essa função prevê, através da comparação intergrupal, o estabelecimento de duas esferas valorativas distintas, sendo o endogrupo associado à polaridade positiva e o grupo opositor, a estereótipos negativos (Tabela 1 - polaridade).

A dinâmica de discriminação social evidenciada pelos estereótipos dos grupos como objetos de representação confirma a existência de um processo de simbolização compartilhado pelos membros do grupo rural no contexto de comparação entre as categorias sociais ruralidade e urbanidade. É necessário, contudo, considerar a dimensão valorativa que mobiliza o campo de produção e difusão dos estereótipos, visto que são a expressão das crenças e dos valores de determinada cultura e sociedade (Sadiqi, 2008). Moscovici, refletindo sobre o processo de discriminação social a partir dos estereótipos negativos relacionados a determinadas minorias, ensina: "Se formos além dos estereótipos ou dos preconceitos, descobriremos sob eles correntes do conhecimento e fórmulas do senso comum, conjuntos de crenças profundamente enraizadas na vida coletiva, mesmo em uma nação moderna" (2009, p. 661).

Torna-se, portanto, uma tarefa necessária refletir sobre a força que mobiliza ou ativa a estereotipia entre os grupos, missão que integra a análise da busca pela proteção da imagem social positiva pelos membros de um grupo social (Tajfel, 1982b, 1983) bem como da posição político-ideológica que este ocupa na estrutura, no imaginário e no pensamento social em determinado contexto cultural, histórico e econômico. Em outras palavras, não basta apenas considerar as representações endogrupais como um dos mecanismos utilizados pelo grupo para arquitetar sua identidade social, mas é necessário identificar as tensões que explicitam a luta entre o hegemônico e o minoritário, matriz relacional que provoca conteúdo defensivo das minorias sociais, como é o caso da comunidade camponesa abordada. Quando, portanto, o grupo rural ressalta como valores que regem os modos de vida no campo aqueles fundamentados nos princípios humanitários e elabora uma crítica ao modo de vida urbano como referenciado pelos interesses do capital, lê-se uma resposta identitária ao megaprojeto de urbanização territorial, econômico e cultural que prevê como necessária a superação das expressões e vivências camponesas, bem como de diversas outras comunidades tradicionais, modos de vida identificados como obstáculo à instituição das sociedades modernas e integradas às metas e propósitos do capital.

\section{Considerações finais}

O estudo abordou a referência entre a elaboração do campo representacional vinculado às categorias sociais ruralidade e urbanidade e o processo de identificação social para membros de uma comunidade rural. Os resultados indicaram a constituição das representações sociais de pessoas do meio rural e pessoas da cidade apoiadas, respectivamente, na dimensão laboral, agrícola, da convivência e das práticas de solidariedade entre as pessoas do endogrupo (atributos característicos do modo de vida comunitário rural) e da esfera capitalista, individualizante e portadora de preconceito em relação à realidade rural no que tange aos sujeitos urbanos, segundo as representações dos entrevistados. Os elementos de representações, nesse sistema, atuam como formas de interpretação da realidade e das relações sociais em curso no domínio do grupo rural, fornecendo subsídios simbólicos para defesa e afirmação da identidade social vinculada à categoria rural.

O estudo evidenciou a relação de interdependência entre os objetos de representação social abordados, confirmando a condição basilar do processo de comparação entre grupos para a elaboração identitária (Brown, 1997, 2000; Tajfel, 1982b, 1983), a coesão simbólica entre as gerações da comunidade, o que sugere a eficácia da socialização para o processo de identificação social referente ao grupo rural, 
e, finalmente, a relação entre identidades e representações sociais como estratégia de análise fundamental para compreender o complexo processo de construção das identidades dos indivíduos e dos grupos sociais, ratificando a proposição psicossocial de interpretação da realidade pautada na relação entre o indivíduo e o seu contexto sociocultural.

Conforme as reflexões que embasaram o estudo, é importante ter em mente que somos herdeiros de uma tradição acadêmica marcadamente urbana (Albuquerque, 2002) e que conhecemos ainda muito pouco sobre como vivem, o que pensam e o que almejam os milhares de brasileiros e de brasileiras que compartilham um modo de vida rural. Apesar das previsões sobre o desaparecimento gradual dos grupos sociais vinculados à categoria rural (Stropasolas, 2006), ao longo do estudo, pudemos constatar um movimento de afirmação da identidade rural que, no jogo simbólico de constituição do campo representacional endo e exogrupal, sublinha as singularidades positivas do grupo e colocaas em relevo frente ao modo de vida das/nas grandes cidades.

Diante de tais considerações, destacamos a relevância de se aprofundar o campo de estudo vinculado à identidade rural a partir da perspectiva do pertencimento psicológico ao grupo (Brown, 1997, 2000; Tajfel, 1982a, 1982b, 1983), o que contribuirá para a compreensão do arranjo políticoideológico característico do movimento de resistência e de afirmação dos grupos sociais, especialmente os que estão à margem das sociabilidades hegemônicas. Dada a diversidade de contextos que expressam as ruralidades brasileiras (Moreira, 2005), enfatizamos ainda a necessidade de se considerar a categoria rural a partir das diferentes realidades territoriais e simbólicas que dão contorno à imagem de uma ruralidade local. Por meio do resgate da memória do grupo, do estudo das práticas educacionais e de saúde, das crenças e tradições celebradas, enfim, das diversas dimensões que se misturam imprimindo um modo de vida àquela comunidade, descortina-se um campo de pesquisa rico e imprescindível ao desenvolvimento de políticas públicas em consonância com as demandas da população envolvida, convite que se impõe como desafio ao desenvolvimento de estratégias metodológicas que possam consolidar a ruralidade como um objeto de estudo também para a Psicologia.

\section{Mariana Bonomo}

Doutora em Psicologia, Pós-Doutoranda em Psicologia pelo Programa de Pós-Graduação em Psicologia da Universidade Federal do Espírito Santo, ES - Brasil.

E-mail: marianadalbo@gmail.com

\section{Lídio de Souza}

Doutor em Psicologia Social, Professor Associado III do Departamento de Psicologia Social e do Desenvolvimento e do Programa de Pós-Graduação em Psicologia da Universidade Federal do Espírito Santo, ES - Brasil.

E-mail: lidio.souza@uol.com.br

\section{Maria Cristina Smith Menandro}

Doutora em Psicologia, Professora Adjunto do Departamento de Psicologia Social e do Desenvolvimento e do Programa de Pós-Graduação em Psicologia da Universidade Federal do Espírito Santo, ES - Brasil.

E-mail: crismenandro@uol.com.br

\section{Zeidi Araujo Trindade}

Doutora em Psicologia, Professora Titular do Departamento de Psicologia Social e do Desenvolvimento e do Programa de Pós-Graduação em Psicologia da Universidade Federal do Espírito Santo, ES - Brasil E-mail: zeidi.trindade@gmail.com

Endereço para envio de correspondência:

Programa de Pós-Graduação em Psicologia Centro de Ciências Humanas e Naturais, Universidade Federal do Espírito Santo Av. Fernando Ferrari, no 514 - Campus Universitário Goiabeiras - Vitória, ES - Brasil - CEP: 29075-910 


\section{Referências}

Abric, J. C. (2001). O estudo experimental das representações sociais. In D. Jodelet (Org.), As representações sociais (pp. 155-171). Rio de Janeiro: EDUERJ.

Abric, J. C. (2003a). De l'importance des réprésentations sociales dans les problèmes de l'exclusion sociale. In J. C. Abric, Exclusion sociale, insertion et prévention (pp. 13-19). Ramonville Saint-Agne: Érès.

Abric, J. C. (2003b). L'analyse structurale des réprésentations sociales. In S. Moscovici, \& F. Buschini (Orgs.), Les méthodes des sciences humaines (pp. 375-392). França: Puf Fondamental.

Albuquerque, F. J. B. (2002). Psicologia social e formas de vida rural no Brasil. Psicologia: Teoria e Pesquisa, 18(1), 37-42.

Aleixo, A. C. V. (2004). A imagem literária de um sertão chamado Brasil. Revista da UFG, 7(01). Recuperado em 15 de dezembro de 2009 de www.proec.ufg.br

Almeida, R. A. (2006). (Re)criação do campesinato, identidade e distinção: a luta pela terra e o habitus de classe. São Paulo: UNESP.

Bahia, J. A. (2001). A "lei da vida": confirmação, evasão escola e reinvenção da identidade entre os pomeranos. Educação e Pesquisa, 27(1), 69-82.

Bardin, L. (2002). Análise de conteúdo. Lisboa: Edições 70.

Bardin L (2003). L'analyse de contenu et de la forme des communications. In S. Moscovici, \& F. Buschini (Orgs.), Les méthodes des sciences humaines (pp. 243-270). Paris: Puf Fondamental.

Brown, R. (1997). Psicologia sociale del pregiudizio. Bologna: Il Mulino.

Brown, R. (2000). Psicologia sociale dei gruppi. Bologna: I Mulino.

Burity, J. (2001). Globalização e identidade: desafios do multiculturalismo. Trabalhos para discussão, n. 107. Recuperado em 30 de novembro de 2009 de http://www. fundaj.gov.br/tpd/107.html.

Cabecinhas, R. (2004). Representações sociais, relaçõe intergrupais e cognição social. Paidéia, 14(28), 125-137.

Cantarelli, J. (2006). Construindo a vida: homens e mulheres em família e a qualidade de vida de camponeses em uma reserva ecológica. In P. Scott, \& R. Cordeiro (Orgs.), Agricultura familiar e gênero: práticas, movimentos e políticas públicas (pp. 279-299). Recife, PE: Ed. Universitária da UFPE.

Cavassani, S. M. C. (1998). A utilização da violência na atividade policial: da insanidade coletiva à loucura solitária. Dissertação de mestrado em Psicologia, Universidade Federal do Espírito Santo, Vitória, ES

Cerqueira, C (2000). Matança do porco, festa da matança mudanças sociais na Serra do Barroso (Trás-os-Montes). In IV Congresso Português de Sociologia. Coimbra: Associação Portuguesa de Sociologia.

Conselho Federal de Psicologia - Resolução CFP no 016/2000. Recuperado em 18 de fevereiro de 2010 de http:// www.pol.org.br/pol/export/sites/default/pol/legislacao/ legislacaoDocumentos/resolucao2000_16.pdf.

Costa, A. F. (2002). Identidades culturais urbanas em época de globalização. Revista Brasileira de Ciências Sociais, 17(48), 15-31.

Doise, W. (2002). La forza delle idee. Bologna: II Mulino.

Flament, C. (2001). Estrutura e dinâmica das representações sociais. In D. Jodelet (Org.), As representações sociais (pp. 173-186). Rio de Janeiro: EDUERJ.

Fressato, S. B. (2008). Cinema-história: teoria e representaçõe sociais no cinema. In J. Nóvoa, \& J. A. Barros (Orgs.), Cultura popular: espaço de deboche e de resistência. Uma representação em tristeza do Jeca (pp. 183-199). Rio de Janeiro: Apicuri.

Galli, I. (2006). La teoria delle rappresentazioni sociali. Bologna: Il Mulino.
Jodelet, D. (1998). A alteridade como produto e processo psicossocial. In A. Arruda (Org.), Representando a alteridade (pp. 47-67). Rio de Janeiro: Vozes.

Jodelet, D. (2001). As representações sociais: um domínio em expansão. In D. Jodelet, As representações sociais (pp. 17-44). Rio de Janeiro: EDUERJ.

Mazzara, B. M. (1997). Stereotipi e pregiudizi. Bologna: Il Mulino.

Moreira, R. J. (2005). Ruralidades e globalizações: ensaiando uma interpretação. In R. J. Moreira (Org.), Identidades sociais: ruralidades no Brasil contemporâneo (pp. 15-40). Rio de Janeiro: DP\&A

Moscovici, S. (2003). Representações sociais: investigações em psicologia social. Petrópolis, RJ: Vozes.

Moscovici, S. (2009). Os ciganos entre perseguição e emancipação. Sociedade e Estado, 24(3), 653-678.

Naiff, D. G., Monteiro, R. C., \& Naiff, L. A. (2009). O camponês e o agricultor nas representações sociais de estudantes universitários. Psico-USF, 14(2), 221-227.

Oliveira, L. L. (2003). Do caipira picando fumo a Chitãozinho e Xororó, ou da roça ao rodeio. Revista USP, 59, 232-257.

Pecora, A. R., \& Sá, C. P. (2008). Memórias e representações sociais da cidade de Cuiabá, ao longo de três gerações. Psicologia: Reflexão e Crítica, 21(2), 319-325.

Rabelo, M. C. M. (2008). Entre a casa e a roça: trajetórias de socialização no candomblé de habitantes de bairros populares de Salvador. Relig. Soc, 28(1), 176-205.

Sá, C. P. (1996). Núcleo central das representações sociais. Petrópolis, RJ: Vozes

Sadiqi, F. (2008). Estereótipos e mulheres na cultura marroquina. Cadernos Pagu, 30, 11-32.

Sawaia, B. B. (2001). Identidade - uma ideologia separatista? In B. B. Sawaia, (Org.), As artimanhas da exclusão: análise psicossocial e ética da desigualdade social (pp. 119-127). Petrópolis, RJ: Vozes.

Silva, M. A. M. (2004). A luta pela terra - experiência e memória. São Paulo: UNESP.

Souza, L (2008). Alteridade, processos identitários e violência acadêmica. In E. M. Rosa, L. Souza, \& L. Z. Avellar (Orgs.), Psicologia social - temas em debate (pp. 169-198). Vitória, ES: UFES-ABRAPSO.

Souza, L., Bonomo, M., Livramento, A. M., Brasil, J. A., \& Canal, F. D. (2009). Processos identitários entre ciganos: da exclusão a uma cultura de liberdade. Liberabit, 15(1), 29-37.

Stropasolas, V. L. (2006). O mundo rural no horizonte dos jovens. Florianópolis, SC: Ed. UFSC.

Suda, J. R., \& Souza, L. (2006). Identidade social em movimento: a comunidade japonesa na grande Vitória (ES). Psicologia e Sociedade, 18(2), 72-80.

Tajfel, H. (1982a). Comportamento intergrupo e psicologia social da mudança. In A. F. Barroso, B. M. Silva, J. Vala, B. M Monteiro, \& M. H. Castro (Orgs.), Mudança social e psicologia social (pp. 13-24). Lisboa: Livros horizonte.

Tajfel, H. (1982b). Grupos humanos e categorias sociais I. (L. Amancio, trad.). Lisboa: Livros Horizonte.

Tajfel, H. (1983). Grupos humanos e categorias sociais II. (L. Amancio, trad.). Lisboa: Livros Horizonte.

Vala, J. (1997). Representações sociais - para uma psicologia social do pensamento social. In J. Vala, \& M. B. Monteiro (Orgs.), Psicologia social (pp. 353-384). Lisboa: Fundação Calouste Gulbenkian.

Vergès, P. (2000). EVOC - Ensemble de programmes permettant l'analyse des évocations: manual version 2. Aix-en-Provence: LAMES. 